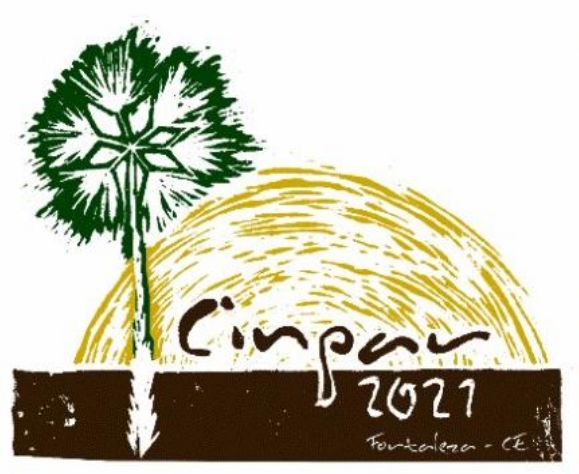

XVII Congresso Internacional sobre Patologia e Reabilitação das Construções

XVII Congreso Internacional sobre Patología y Rehabilitación de las Construcciones

XVII International Conference on Pathology and Constructions Rehabilitation

FORTALEZA (Brasil), 3 a 5 de junho de 2021

https://doi.org/10.4322/CINPAR.2021.091

\title{
Inspeção e Análise de Patologias em Pontes de Concreto: Estudo de Caso em Rio Branco, Acre
}

\section{Inspection and Analysis of Pathologies on Concrete Bridges: Case Study in Rio Branco, Acre}

\author{
Arquiney Augusto Rodrigues MAIA', Nalbhert Albuquerque VIANA², Antonia Alana LIMA PACHECO ${ }^{3}$ \\ ${ }^{1}$ Centro Universitário UNINORTE, Rio Branco - AC, Brasil, aarquiney@gmail.com \\ ${ }^{2}$ Centro Universitário UNINORTE, Rio Branco - AC, Brasil, nalbhert@gmail.com \\ ${ }^{3}$ Escola Politécnica da Universidade de São Paulo, São Paulo - SP, Brasil, alanapacheco@usp.br
}

\begin{abstract}
Resumo: Como qualquer outra estrutura, as pontes se deterioram com o tempo e necessitam de programas de inspeção e manutenção periódica para garantir sua funcionabilidade. No Brasil, a prática de manutenção em pontes e viadutos ainda é falha e isso pode ser observado pelo grande número de pontes com manifestações patológicas, resultando em onerosos gastos de recuperação. Nesse contexto, o presente trabalho inspeciona as manifestações patológicas presentes em uma ponte rodoviária na cidade de Rio Branco, Acre, com o objetivo de analisar o estado de conservação de sua estrutura. Para isso, foram feitas visitas ao local, registro fotográfico e aplicação de uma ficha de verificação baseada na norma de inspeção em pontes e viadutos na ponte do estudo de caso. As principais manifestações patológicas encontradas na ponte foram pontos de infiltração, fissuração, lixiviação e corrosão em alguns elementos estruturais. Os apoios e juntas de dilatação estavam desgastados, o sistema de drenagem estava ineficaz e ainda havia presença de vegetação na estrutura, além da ausência de elementos de segurança e processos erosivos nos taludes. Por fim, observou-se que a ponte apresenta diversas patologias que não comprometem diretamente sua estrutura, mas que se não forem corrigidas a médio prazo podem se desenvolver, comprometendo a sua estrutura e reduzindo drasticamente a vida útil e a durabilidade da ponte.
\end{abstract}

Palavras-chave: Concreto. Inspeção. Manutenção. Patologia. Pontes.

\begin{abstract}
Like any other structure, bridges deteriorate over time and require periodic inspection and maintenance programs to guarantee their functionality. In Brazil, the practice of maintenance on bridges and viaducts is still missed and consequently there are many bridges with pathological manifestations, resulting in onerous recovery costs. In this context, the present work inspects the pathological manifestations on a road bridge in the city of Rio Branco, Acre, with the objective of analyzing the state of conservation of its structure. For this, it was conducted technical visits with photographic registration on the bridge of the case study and the application of a verification form based on the bridges and viaducts inspection standard. The main pathological manifestations found on the bridge were points of infiltration, cracking, leaching and corrosion in some structural elements. The supports and expansion joints were deteriorated, the drainage system was ineffective and there was still vegetation in the structure, in addition to the absence of safety elements and erosion processes on the slopes. Finally, it was observed that the bridge had several pathologies that do not directly affect its structure, but if not corrected in the medium term they can develop, compromising its structure and drastically reducing the life cycle and durability of the bridge.
\end{abstract}

Keywords: Concrete. Inspection. Maintenance. Pathology. Bridges. 


\section{Introdução}

As Obras de Arte Especiais (OAEs), assim como qualquer edificação, também se deterioram com o tempo e necessitam cuidados para garantir sua funcionabilidade (Giovanneti, 2014). Apesar de existirem programas voltados à manutenção, geralmente não há completa aplicação desses programas e as intervenções somente são feitas quando a estrutura está quase atingindo seu limite de utilização, resultando em onerosos gastos de reparação, que podem ser evitados com a correta inspeção e cuidados (Vitório, 2015).

Em pontes, as patologias se manifestam de forma intensa e significativa, resultando na redução da capacidade resistente e no comprometimento dos aspectos estéticos, podendo levar a estrutura ao colapso. A prolongação da vida útil, do desempenho estrutural e funcional aceitável só é possível através de programas de conservação de gestão e manutenção, aliados a fiscalizações periódicas que visam indicar falhas e ações de recuperação e manutenção na estrutura (Helene, 1992).

Dentre as manifestações patológicas mais comuns em pontes de concreto, podemos destacar as fissuras, que tem interferência direta na durabilidade, na estética e na capacidade estrutural da edificação (Carmona, 2005). A corrosão das armaduras, que está relacionada ao tipo ambiente em que a estrutura se encontra (DNIT, 2016). A abrasão, comum nos pilares, ocasionada pela perda de material na superfície devido ao choque de partículas que são levadas pela água dos rios (Andrade, 2005). Há também a biodegradação do concreto, ocasionado pela ação de microrganismos que se desenvolvem nos poros do concreto (Mendes, 2009). Outro ponto são as falhas no sistema de drenagem, pois geram pontos de acúmulo de água e infiltração que ao longo do tempo, podem danificar o concreto (Vitório, 2007). O uso contínuo da estrutura também acaba provocando danos como irregularidades no pavimento e desníveis nas juntas de dilatação, deterioração do tabuleiro e danos aos dispositivos de segurança da obra (DNIT, 2016).

Nesse cenário, a presente pesquisa buscou inspecionar e investigar a ocorrência de manifestações patológicas em uma ponte rodoviária da cidade de Rio Branco - Acre, a Terceira Ponte de Rio Branco, buscando um panorama do seu atual estado de conservação. O estudo utilizou como base a Norma Brasileira (NBR) 9452/2019 - Inspeção de pontes, viadutos e passarelas de concreto, para análise da ponte em relação a seus elementos estruturais e de que maneira as manifestações patológicas podem afetar a durabilidade e funcionalidade da construção.

\section{Metodologia}

A metodologia empregada neste trabalho foi do tipo estudo de caso, dividido em: definição do objeto de estudo de caso, inspeção visual, análise das patologias e análise do estado de conservação da estrutura. A ponte escolhida para o estudo de caso está localizada sob o Rio Acre, no loteamento Praia do Amapá, na cidade de Rio branco - Acre (Figura 1). Ela é parte integrante do anel viário da região, que através da BR 364 liga os dois distritos da cidade, servindo como um desvio para veículos de grande porte, aliviando o trânsito de cargas pesadas na região central de Rio Branco.

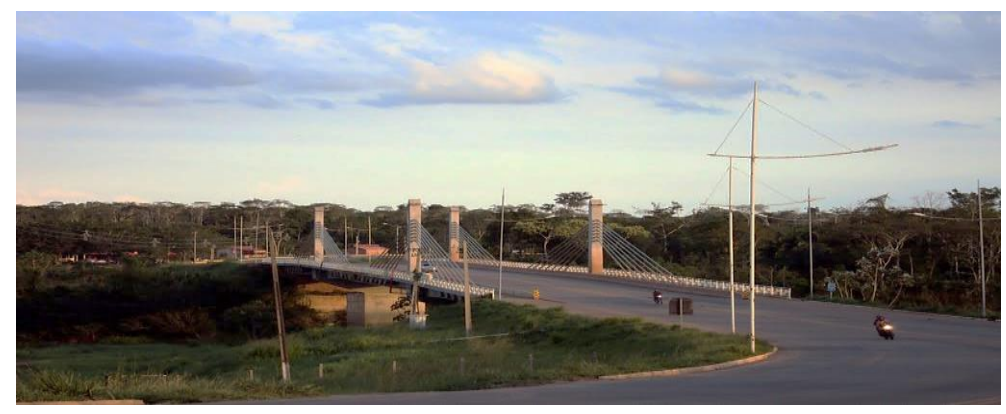

Figura 1 - Terceira ponte de Rio Branco (Google Maps, 2021)

A estrutura se caracteriza por ser uma ponte rodoviária do tipo reta ortogonal com altimetria horizontal e sistema estrutural de protensão no extradorso e seu sistema construtivo foi o de balanços sucessivos. A estrutura é constituída por dois vãos de $54 \mathrm{~m}$ e um vão central de $90 \mathrm{~m}$, totalizando $198 \mathrm{~m}$ de comprimento (Figura 2). A ponte comporta duas pistas de $17,40 \mathrm{~m}$ de largura, com duas faixas de tráfego cada. Os pilares 
que sustentam o vão principal tem $10 \mathrm{~m}$ de altura e são do tipo parede e possuem estruturas de proteção nas extremidades, para evitar o acúmulo de resíduos trazidos pelo rio. A fundação dos pilares é composta por blocos de coroamento apoiados em tubulões escavados sob ar comprimido. Os encontros da ponte são formados por vigas travessas, que se apoiam sobre tubulões e incorporam uma cortina de contenção do aterro de acesso a estrutura. Esses ainda sustentam as longarinas através de aparelhos de apoio metálico (tipo freyssinet) que permitem movimentações e sustentam a laje de aproximação (Oyamada, 2005).

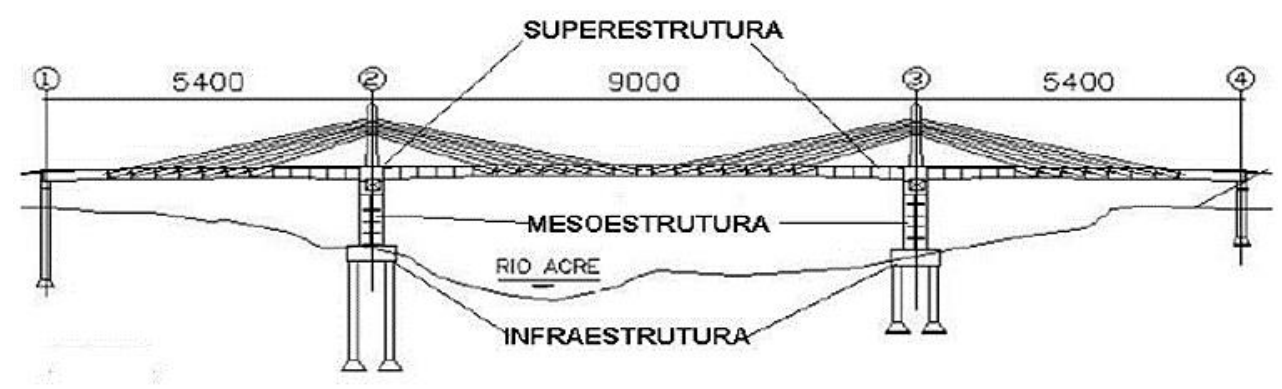

Figura 2 - Vista lateral da ponte (Oyamada, 2005).

\subsection{Inspeção visual e análise das patologias}

Com o objetivo de ter uma análise mais abrangente desde a infra até a superestrutura, as visitas ao local foram feitas no período de estiagem do Rio Acre, em outubro de 2019, onde o nível do rio oscilava entre as cotas de 1,60 a 2,00 metros, deixando assim todos os elementos da estrutura visíveis. Para a inspeção visual foram utilizados smartphone, máquina fotográfica, trena métrica e a Ficha de Inspeção Cadastral (FIC), disponível na NBR 9452 (ABNT, 2019).

A FIC foi escolhida por ser a primeira inspeção que deve ser realizada em uma obra, compreendendo ao registro de informações gerais como classificação da estrutura, identificação, localização e características da edificação, bem como o registro de anomalias em três segmentos: elementos estruturais (super, meso e infraestrutura, aparelhos de apoio, juntas de dilatação e encontros); elementos da pista (pavimento, acostamento, drenagem, guarda-corpo e defensas metálicas); e outros elementos (taludes, iluminação, sinalização, gabaritos, proteção de pilares).

A análise das patologias se deu através da interpretação dos dados obtidos pela FIC e das fotografias feitas no local. As manifestações patológicas encontradas na ponte foram comparadas com a literatura para a compreensão das causas dos fenômenos apresentados e seus possíveis agravamentos na edificação.

\subsection{Análise do estado de conservação da ponte}

Para a análise do estado de conservação da ponte, foram levados em consideração os sintomas apresentados pela estrutura e as recomendações da NBR 9452 (ABNT, 2019). Foi atribuída uma nota à OAE, analisando os parâmetros estruturais, funcionais e de durabilidade. A esses parâmetros, foram associadas notas de classificação, pré-estabelecidas em norma, variando de 1 a 5 , refletindo maior ou menor gravidade dos problemas detectados, em excelente, boa, regular, ruim ou crítica.

\section{Estudo de Caso}

\subsection{Inspeção e análise das patologias}

As patologias analisadas foram classificadas em elementos estruturais, elementos de pista e outros elementos. Para um melhor entendimento da localização das patologias na estrutura, foi elaborado um mapa de patologias, que se encontra disponível no Apêndice A deste artigo.

\subsection{1 - Elementos estruturais}

Na laje inferior da superestrutura (Figura 3a) foram identificados pontos de armadura exposta, onde foi possível observar manchas avermelhadas que demonstram pontos de corrosão na armadura e sinais de 
processos químicos que indicam carbonatação ou eflorescência, representados pelas manchas brancas (Figura 3b). A corrosão resulta na diminuição da área de aço e pode em grau elevado, levar a estrutura ao seu estado limite último (Helene, 1992).

(a)

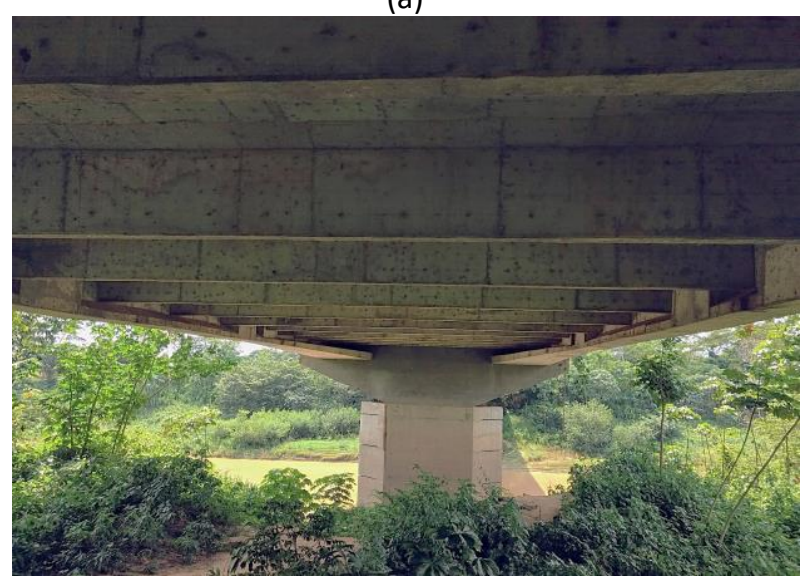

Figura 3 - Laje inferior da superestrutura (b)

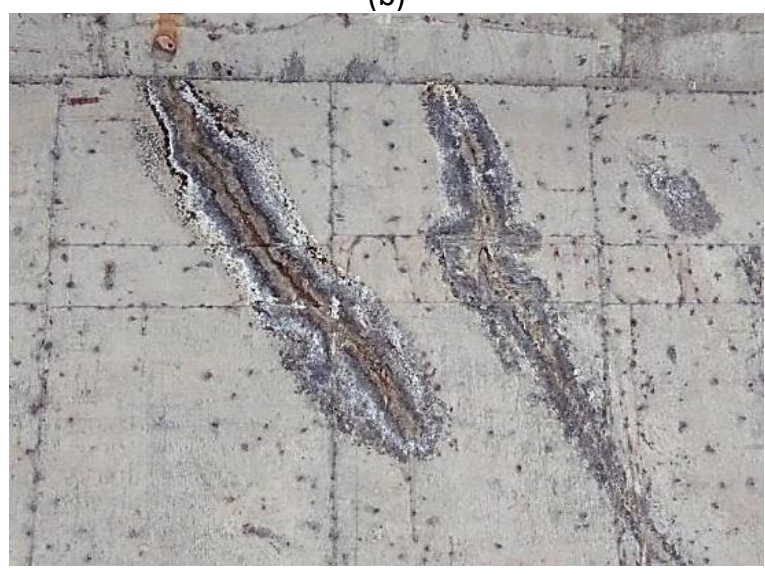

Figura 3 - Armadura espostacom sinais de corosão e processos de químicos

Ainda na superestrutura, encontrou-se a formação de estalactites tanto na laje como nos nichos de protensão da estrutura (Figura 4a), possivelmente originadas devido à lixiviação em decorrência da presença de umidade no local. Além disso, devido à falta de manutenção na estrutura, a ponte apresenta vários pontos cobertos por vegetação, (Figura 4b). Na parte inferior da superestrutura, há presença de raízes com comprimentos maiores que 1 metro, que podem vir a causar a biodeterioração do concreto. As raízes crescem nas fendas e locais porosos da estrutura contribuindo com a entrada de agentes agressivos em seu interior (Mendes, 2009).

(a)

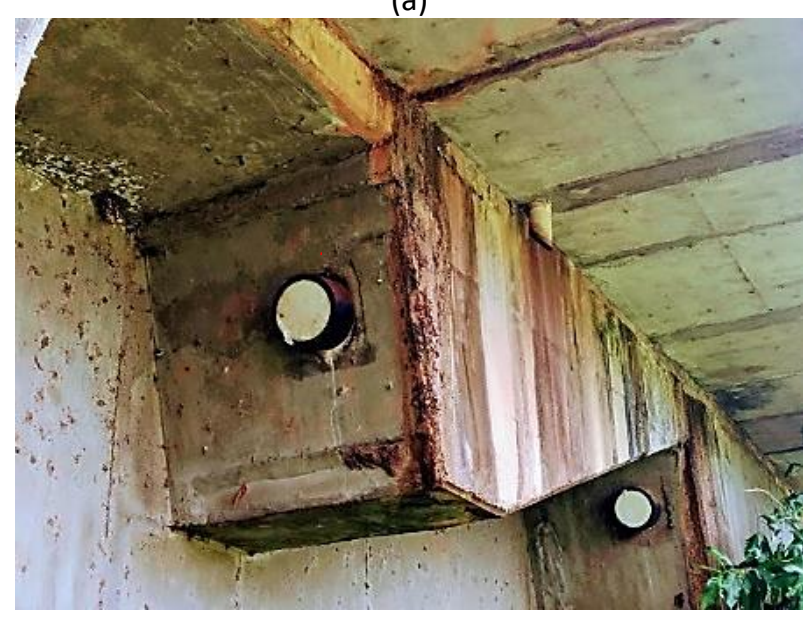

Figura 4 - Nicho de estaio com pontos de lixiviação, infiltrações e estalactites (b)

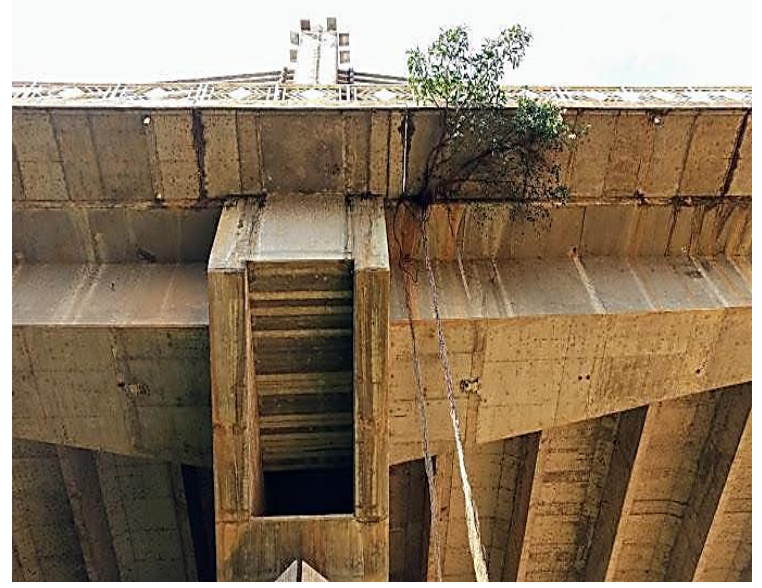

Figura 4 - Desenvolvimento de vegetação na estrutura da ponte

Na mesoestrutura, os pilares apresentaram bom estado de conservação, com alguns pontos de desgaste superficial e surgimento de fissuras. Já os aparelhos de apoio se encontraram em elevado grau de deterioração (Figura 5a) com rasgos na camada superficial e exposição das chapas metálicas, além de manchas de infiltração em uma base deteriorada. Na contenção da estrutura, o muro ala apresentava sinais de infiltrações (Figura 5b) provavelmente oriundas de falhas no sistema de drenagem.

Na Figura 6a é possível observar os tubulões da infraestrutura, que se encontravam visíveis em virtude da erosão localizada nos elementos de fundação. Eles apresentaram bom estado de conservação, sem presença de armaduras expostas, mas o bloco de coroamento apresenta marcas de desgaste por abrasão e fissuras (Figura 6b). 
(a)

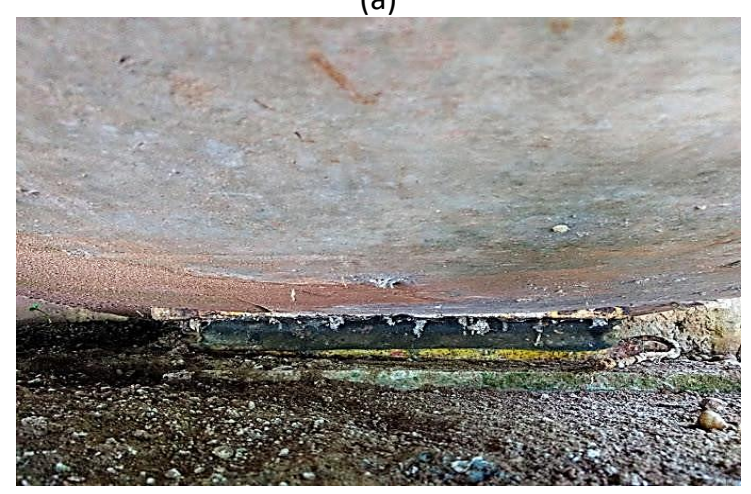

Figura 5 - Aparelho de apoio desgastado

(a)

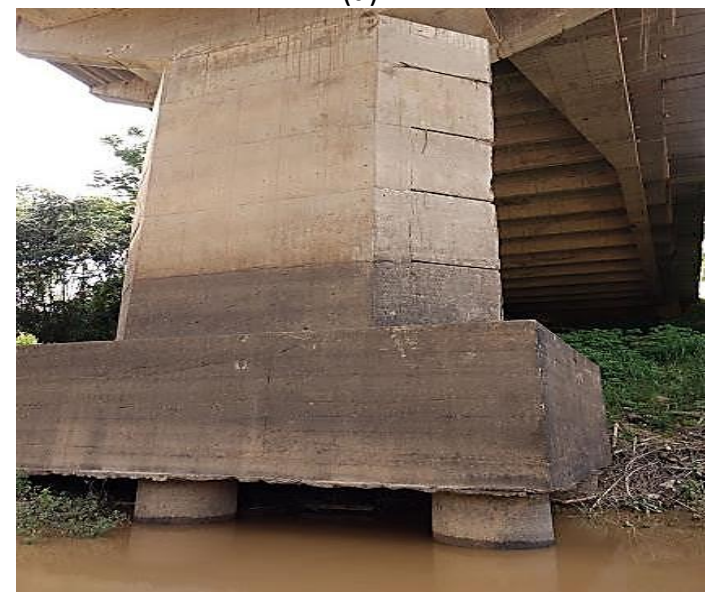

Figura 6 - Pilar, tubulão e bloco de coroamento (b)

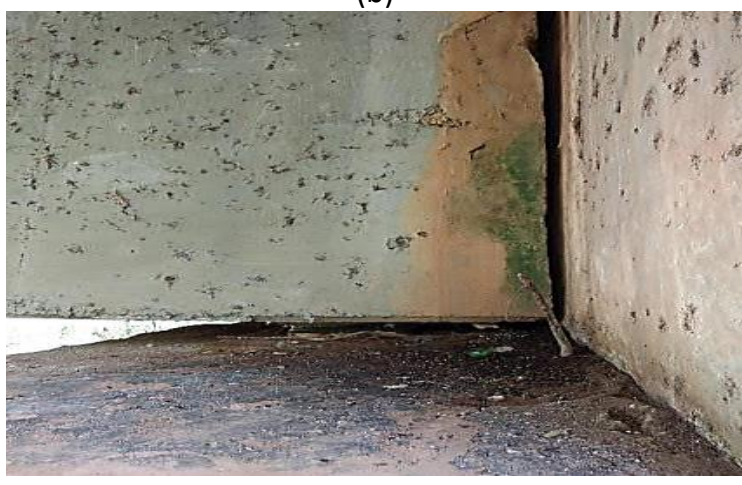

Figura 5 - Encontro viga-contenção, presença de manchas de infiltração

(b)

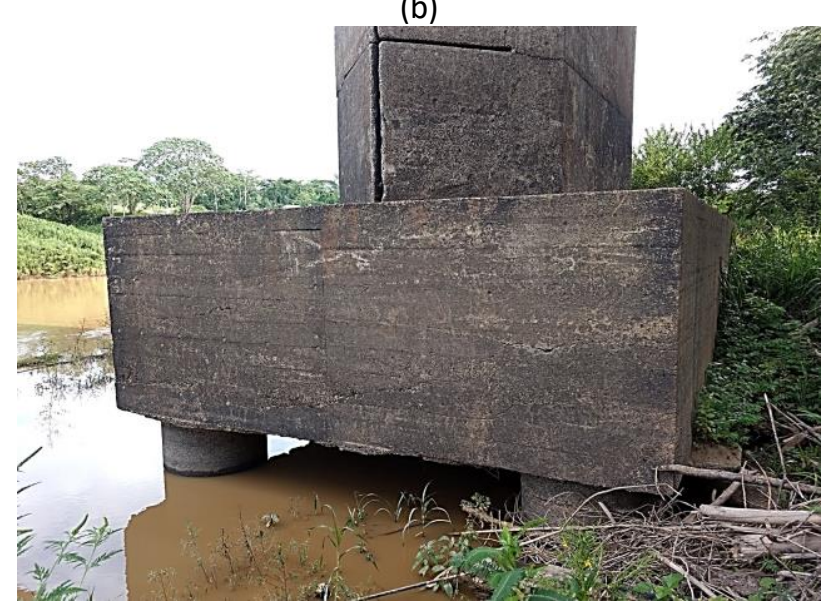

Figura 6 - Bloco de coroamento com marcas de abrasão e fissuras

\subsection{2 - Elementos de pista ou funcionais}

As juntas de dilatação de transição da estrutura apresentaram desgaste e já não possuíam o material de preenchimento (Figura 7a) que cedeu devido ao alto grau de deterioração do elemento, dando lugar ao acúmulo de detritos e vegetação (Figura $7 \mathrm{~b}$ ) nos espaços em que deveriam possuir o material. A falta do material pode gerar desconforto ao transeunte resultar em danos ao tabuleiro e o revestimento, pois não permitem que as dilatações aconteçam de forma correta (DNIT, 2016).

(a)

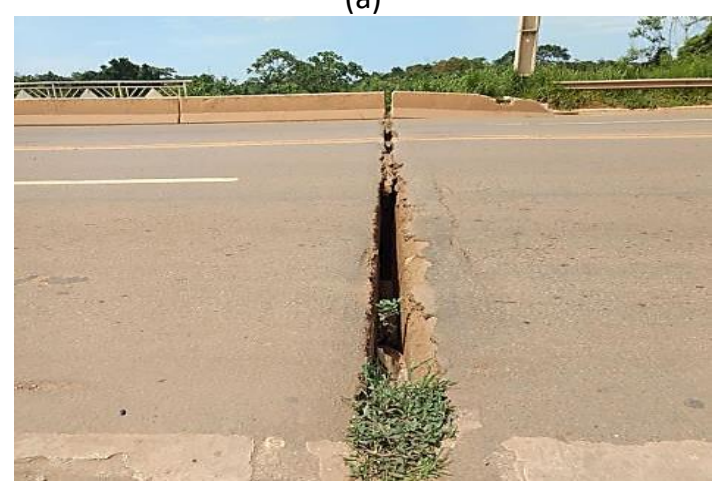

Figura 7 - Junta de dilatação sem material de preenchimento (b)

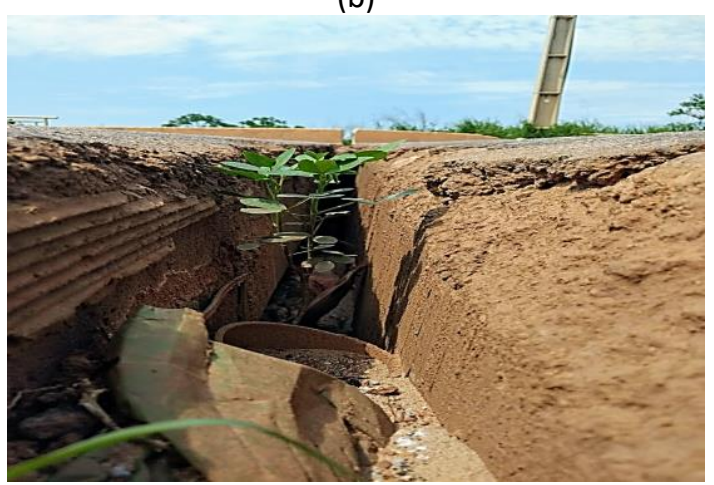

Figura 7 - Restos do antigo material de preenchimento e acúmulo de detritos no local destinado a junta

O sistema de drenagem da estrutura apresentou pontos de acúmulo de detritos e desenvolvimento de vegetação nos canos (Figura 8a) obstruindo a drenagem e causando acúmulo de água, que poderiam resultar 
no desenvolvimento de patologias ao longo da estrutura. Os guarda-corpos se encontravam deteriorados, apresentando ferrugem e corrosão em várias partes (Figura 8b), podendo oferecer risco à segurança dos pedestres. Ainda foram encontrados lugares aonde o guarda-corpo estava ausente na estrutura.

(a)

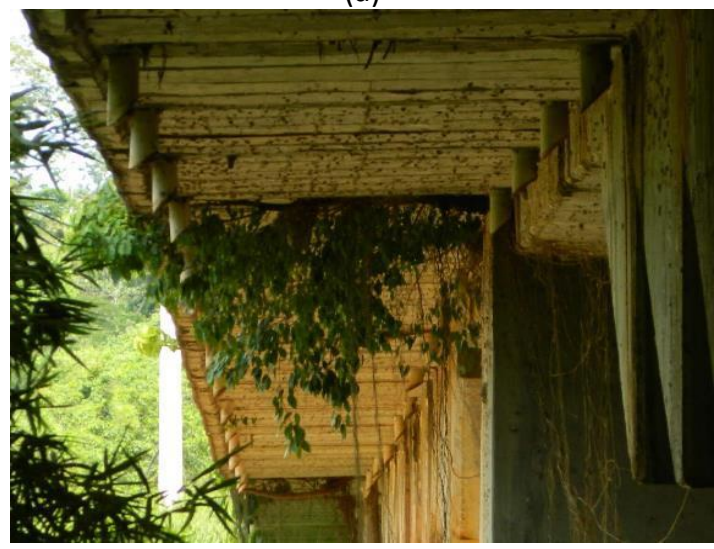

Figura 8 - Sistema de drenagem obstruido pela vegetação (b)

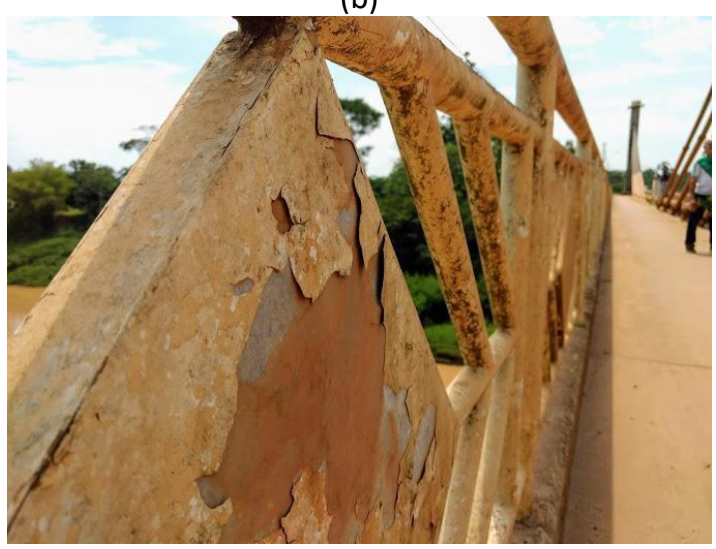

Figura 8 - Guarda corpo em deterioração

As barreiras de concreto do tipo New Jersey apresentavam problemas como ferragem exposta, sessões danificadas e buracos, proveniente de colisões com veículos e furtos de cabos de energia da estrutura. As defensas metálicas, presentes em ambos os lados da ponte, estavam em perfeito estado na data da visita.

\subsection{3 - Outros elementos}

A Figura 9a mostra problemas de erosão nos taludes da edificação, possivelmente devido às chuvas ou enchentes. Essa erosão pode acarretar o desconfinamento da fundação e consequentemente trazer danos à estrutura, uma vez que o desconfinamento faz com que parte da estrutura fique exposta, reduzindo assim seu atrito lateral (Vitório, 2015). Os pilares possuem estruturas de proteção em forma de ' $V$ ', que são uma alternativa para evitar o acúmulo e choque de partículas na estrutura em épocas de enchente. Essas estruturas de proteção apesentavam rachaduras (Figura 9b), armaduras expostas e danos, que indicavam necessidade de manutenção.

(a)

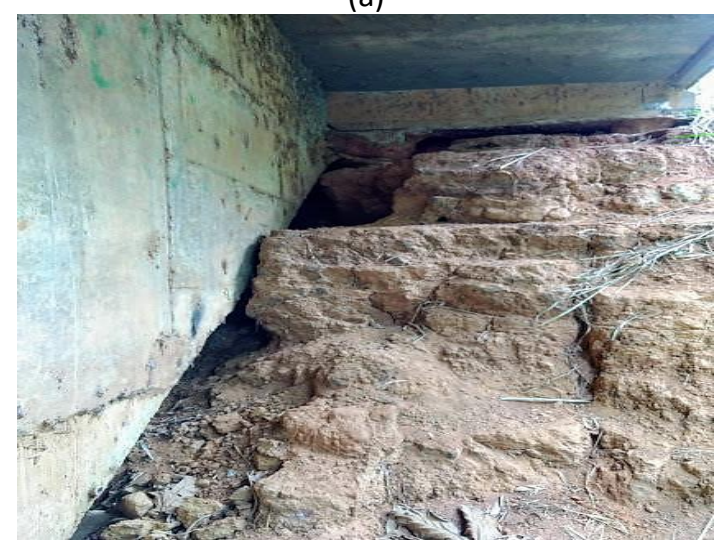

Figura 9 - Processos erosivos no talude da edificação (b)

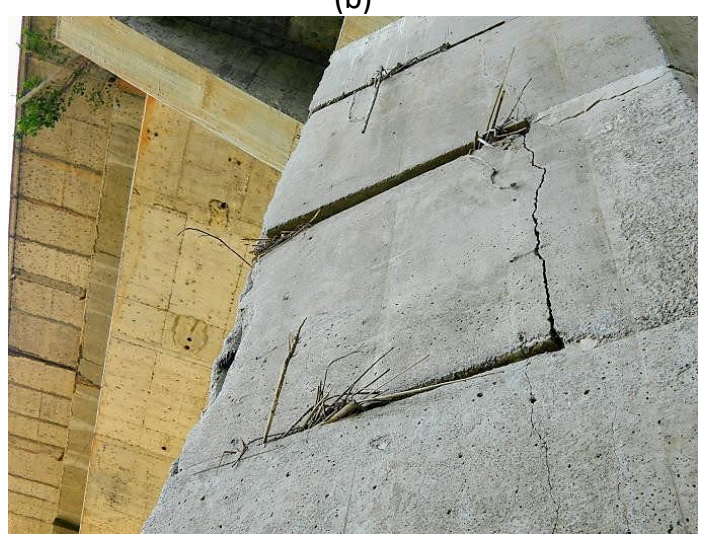

Figura 9 - Estrutura de proteção dos pilares

\subsection{4-Resumo}

O Quadro 1 apresenta um resumo das principais manifestações patológicas observadas na ponte. 
Quadro 1 - Resumo das manifestações patológicas encontradas

QUANTO À ESTRUTURA

Superestrutura: Armadura exposta na laje inferior; pontos de lixiviação e infiltração; presença de vegetação em longarinas e transversinas.

Mesoestrutura: Pilares com fissuras; desgaste superficial; pontos de segregação de concreto.

Infraestrutura: Algumas fissuras e pontos de segregação.

Aparelhos de apoio: Desgastados; presença de corrosão das chapas metálicas; acúmulo de sujeira.

Encontros: Muros alas apresentam algumas fissuras.

\section{QUANTO AOS ELEMENTOS DE PISTA/FUNCIONAIS}

Juntas de dilatação: Danos severos causando desconforto ao usuário; pontos com ausência do material de preenchimento.

Drenagem: Sistema de drenagem falho, água contida na estrutura levando o surgimento de quadros patológicos.

Guarda-corpo: Com sinais de corrosão e desgaste superficial; ausente em alguns pontos da estrutura.

Barreiras de concreto/Defensa metálica: Deterioradas; pontos de armadura exposta.

\section{OUTROS ELEMENTOS}

Taludes: Pontos de erosão significativa acarretando o desconfinamento da fundação. Iluminação: Inexistente; Nenhum ponto de iluminação; Nichos de iluminação danificados.

Proteção de Pilares: Estruturas de proteção com rachaduras, armaduras expostas e extremamente danificadas, podem vir a se tornar caminho de entrada para agentes agressivos externos.

\subsection{Análise do estado de conservação}

Nos parâmetros estruturais, aqueles relacionados à segurança estrutural da OAE, como capacidade portante, estado limite último e de utilização, a Terceira Ponte de Rio Branco foi classificada com nota 3, apresentando uma condição regular. Logo, existem danos que podem vir a gerar alguma deficiência estrutural, mas não há sinais visuais de comprometimento da estabilidade da obra. Recomenda-se nesse caso, o acompanhamento dos problemas, pois intervenções podem ser necessárias a médio prazo.

Em relação ao desempenho funcional, que são aspectos relacionados aos fins que a edificação se destina, proporcionando conforto e segurança aos usuários, onde são analisados depressões, guarda-corpos e sinalização adequada, à estrutura foi atribuída nota 3. Isso significa que a OAE apresenta desconforto ao usuário, com defeitos que requerem ações a médio prazo.

Por fim, quanto ao parâmetro de durabilidade, onde são analisadas características associadas à vida útil da estrutura, tempo estimado de serviço e resistência contra ataques de agentes ambientais agressivos, como corrosões, fissurações, erosões em taludes de encontros, a estrutura foi classificada com a nota 4. Essa nota foi atribuída pois a ponte apresenta pequenas e poucas anomalias que comprometem sua vida útil, em região de baixa agressividade ambiental.

\section{Conclusões}

A Terceira Ponte de Rio Branco apresenta manifestações patológicas em todos seus elementos estruturais, funcionais e outros. Dentre os elementos estruturais, deve-se dar maior destaque à armadura exposta na laje inferior, aos aparelhos de apoio que se encontram desgastados e às juntas de dilatação que não possuem mais preenchimento. Nos elementos pista e funcionais, foi evidenciado problemas de drenagem que resultam em pontos de infiltração, lixiviação e carbonatação na estrutura. Há também a ausência de manutenção nos elementos de segurança como guarda-rodas e guarda-corpo. Por fim, nos outros elementos, foram encontrados processos erosivos nos taludes e as estruturas de proteção dos pilares, se encontram danificadas, com rachaduras e deslocamentos de placas.

Considerando que o propósito do trabalho foi avaliar o estado de conservação da ponte, pode-se observar que as condições da obra de arte especial estão regulares. Entretanto, a obra necessita de cuidados em pontos específicos, pois apesar de não existirem sinais visíveis de comprometimento estrutural no atualmente, eles podem causar novas patologias, reduzindo gradualmente a vida útil e a durabilidade da estrutura. 


\section{Agradecimentos}

Os autores agradecem ao Centro Universitário UNINORTE, onde o trabalho foi inicialmente desenvolvido. Antonia A. L. Pacheco agradece ao CNPq (bolsa número 140054/2020-0).

\section{Referências Bibliográficas}

ABNT, ASSOCIAÇÃO BRASILEIRA DE NORMAS TÉCNICAS (2019). NBR 9452 - Inspepção de pontes, viadutos e passarelas de concreto - Procedimento. Rio de Janeiro.

Andrade. T.; Silvam A. J. C. (2005). Patologia das Estruturas. Concreto: ensino, pesquisa e realizações. São Paulo.

Carmona F. A. (2005). Curso Prático de Diagnóstico, Reparo, Reforço e Proteção de Edificações em Concreto. Abece. São Paulo.

DNIT, DEPARTAMENTO NACIONAL DE INFRAESTRUTURA DE TRANSPORTES (2016). Manual de Manutenção em Obras de Arte Especiais. 1eed. Rio de Janeiro.

Giovannetti, A. C. V. (2014). Avaliação da Condição de Conservação de uma Ponte - Estudo de caso. Tese de Mestrado. Universidade Federal de Santa Catarina, Florianópolis.

Helene, P. R. L (1992). Manual para Reparo, Reforço e Proteção de Estruturas de concreto. 2åed. Rio de Janeiro.

Mendes. P. T. C. (2009). Contribuição para um Modelo de Gestão de Pontes de Concreto Aplicado à Rede de Rodovias Brasileiras. Tese de Mestrado. Escola Politécnica da Universidade de São Paulo, São Paulo.

Oyamada, R. N. (2005) - Ponte Protendida no Extradorso (Extradosed) sobre o Rio Acre. Simpósio IberoAmericano o Betão nas Estruturas - SIABE 05 Coimbra, Portugal; julho 2005.

Vitório, A. (2015) - Curso de Especialização em inspeção, manutenção e recuperação em estruturas. Escola politécnica de Pernambuco Programa de Pós-Graduação em Engenharia. Pernambuco.

\section{Apêndice A - Mapa das patologias na estrutura}

No mapa abaixo, estão representados desenhos esquemáticos da estrutura, com a posição das patologias identificadas no presente artigo, em sua real localização na Terceira Ponte. As patologias estão representadas conforme $o$ número da figura indicada na presente pesquisa. A legenda abaixo indica através de cores cada elemento analisado.

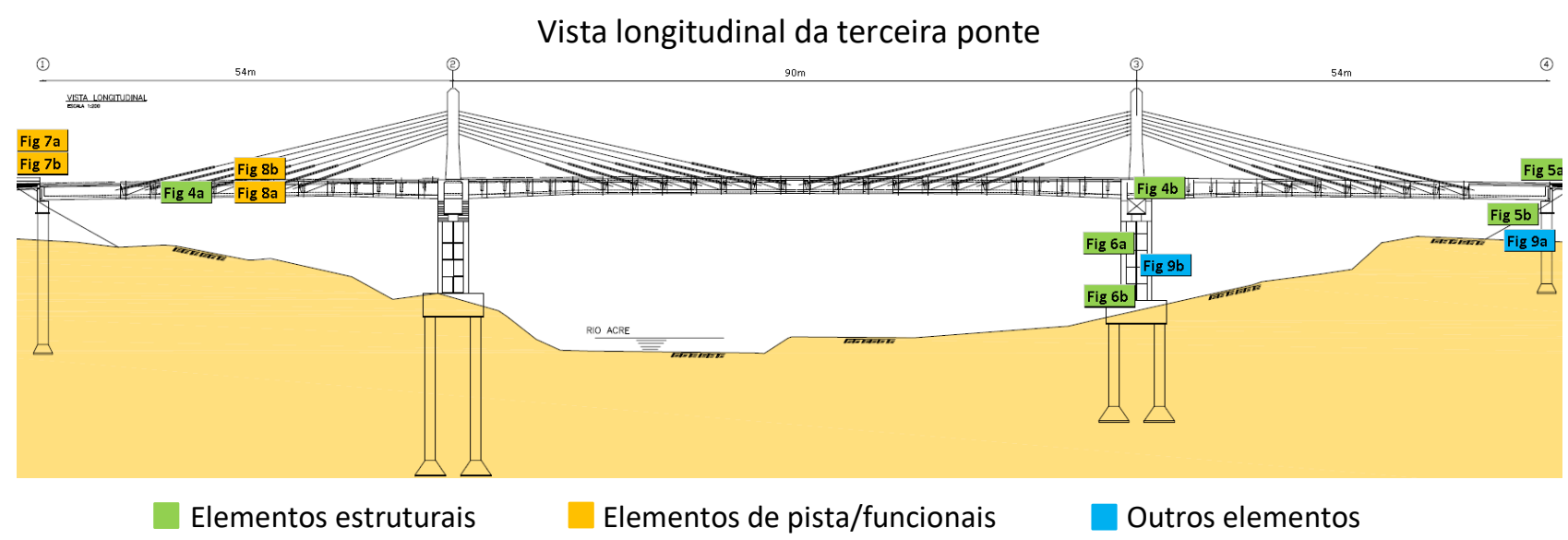

Inspeção e Análise de Patologias em Pontes de Concreto: Estudo de Caso em Rio Branco, Acre 